Article

\title{
What Is a Family and Why Does It Matter?
}

\author{
Esther Dermott ${ }^{1, *}$ (i) and Tim Fowler ${ }^{2}$ \\ 1 School for Policy Studies, University of Bristol, Bristol BS8 1QU, UK \\ 2 School for Politics, Sociology and International Studies, University of Bristol, Bristol BS8 1QU, UK; \\ tim.fowler@bristol.ac.uk \\ * Correspondence: esther.dermott@bristol.ac.uk
}

Received: 20 February 2020; Accepted: 5 May 2020; Published: 14 May 2020

\begin{abstract}
The family is increasingly a site of political intervention as a locus of pervasive social inequalities and a potential resource for resolving injustices. Contemporary political theory has engaged in extensive debate about what justice in the family requires, but rather less on how family is understood: ethicists have tended to use placeholder definitions which dismiss the need to engage with real-world practices. We show that this is problematic because it obscures morally important aspects of day to day family life and risks taking privileged positions as representative. The paper proposes that theorists could gain from adopting the sociological 'family practice' framework, which we argue can form the basis of a distinct and plausible ethical theory of family. This can provide a fruitful basis for further research and engagement in political debate because it better conceptualizes contemporary family life. The paper therefore also illustrates how research from empirical social sciences can be helpful to the development of normative principles.
\end{abstract}

Keywords: parenting; family practices; ethics; normative; political theory

\section{Introduction}

Recent debates within family ethics ${ }^{1}$ have shown considerable interest in the source and scope of the parent-child relationship in order to define rights and obligations between parents and children. These accounts present us with different versions of who should count as a parent and the limits of parental authority. Either implicitly or explicitly 'family' in this literature is understood to be almost exclusively, and unproblematically, synonymous with an institution in which adults are raising children. This paper firstly interrogates this construction of 'family' and its use in contemporary society, and secondly advocates for a shift in family ethics by understanding family as a set of social practices. This approach explicitly draws on concepts from family sociology in order to show how sociological thinking can make a contribution to discussions of how people should act.

We argue that this move has important advantages. Conceptually, it offers a broader definition of 'family' i.e., one that is not artificially narrowed and therefore allows for relationships that are not between parents and children to be taken seriously and as having deep moral/ethical significance. The family practices framework roots our understanding of what family is in everyday expectations and behaviours, and thereby connects the abstract concept to the way it is used by social actors: since 'family' is necessarily a social construct, this is of central importance. We use this framework to explain the ethical importance of familial relationships, in particular, why they create moral obligations, and show that this cannot be reduced to either blood relations or to previous choices.

1 By family ethics we mean work within applied ethics including bioethics and analytic political philosophy that addresses issues of value and moral action in relation to families and in particular the raising of children. 
The paper initially describes how existing philosophical literature tends to restrict discussions of the family only to the parent child relationship. In so doing, 'the family' is presented as a static institution with a defined purpose: the raising of children. This work has been important in highlighting vitally important moral questions, such as the limits of parental partiality (Brighouse and Swift 2014), or what properties give an adult claims to parent a particular child (Gheaus 2018). Beyond this, we suggest there are practical and important normative questions which family ethicists should address that require a different methodological approach and, consequently, definitions of families. Our approach draws on the sociological concept of 'family practices' which understands families as being dynamic and constituted by the activities of members rather than being defined through legal or blood ties, as such it recognises the salience of cultural contexts to both reconfirm and alter meanings of family. Thus, in common with a number of other prominent writers (e.g., Brighouse and Swift 2014), our approach moves away from biological conceptions of family. It also challenges the version of 'families of choice' echoed in recent philosophical work e.g., (Chambers 2017; Cutas and Chan 2012) according to which individual agency is central and families are created solely through subjective ideas of belonging. In our approach, following the definition provided by Morgan (1996) and more recently Finch (2007), the doing of family is central; families are sites of bundles of activities through which relationship statuses are embedded, reproduced or challenged.

\section{Restricting 'Family'}

Leading theorists of family customarily begin their discussions by stipulatively narrowing their focus to stereotypical family relations, most commonly the parent-child dyad. David Archard, whose approach is typical within the field of applied ethics in that definitions are restricted to 'simple' cases rather than engaging with the complexity of contemporary practice, writes that a family is 'a multigenerational group, normally stably co-habiting, whose adults take primary custodial responsibility for dependent children' (Archard 2010a, p. 10-11). Archard notes the complexity of modern family life, but argues that this circumscribed account is a sufficient starting point for philosophical analysis on questions of family. Indeed, he gives little space to considering different definitions of the family as his interest is in exploring issues of parental rights and responsibilities over children.

Similarly, Brighouse and Swift (2014) work on 'Family values' is in fact restricted to a discussion of the values that are realised by the parenting of children. They recognise that there are other relationships which we commonly refer to as familial, but suggest that these ought to be excluded for the purposes of their theory writing 'it's important to think of our stipulating parent-child relationships as the key element in 'family values' as motivated only by a desire for analytical focus on what we take to be particularly theoretically interesting issues. It is by no means an ideological intervention claiming 'the family' for the project of bearing and raising children' (2014, p. 48).

Our paper could be interpreted as offering a way of thinking about families in order to address a different set of theoretical questions around rights and responsibilities for care which have practical importance but which are necessarily pushed aside when the focus is on limited case of parents and their dependent children. For instance, the rights and responsibilities of 'extended' families, or of adults who are intimately involved in the care of children but not commonly considered their parents (e.g., MacDonald et al. 2018; Powell 2018). As such, it can be read as extending previous debates on 'family values' to a wider set of social relationships that more accurately reflects the reality of family life. Other definitions tend to rely on a 'common sense' understanding of empirical realities which, even when noting the limitations of the 'nuclear family', then largely ignore structural variations and so continue to support an outdated depiction of 'normal' families.

However, we also argue that even for those focused exclusively on questions of parent-child relationships there is value in our approach, since it provides a better understanding of who counts as a parent. Here we intervene in an existing debate on how adults come to have a bundle of rights and obligations with respect to a particular child. Competing accounts include the causal theory 
of parenthood (Porter 2014; Austin 2007), gestational accounts which locate parenting in pregnancy (Gheaus 2018) or genetic approaches (Velleman 2005). Each of these theories offer competing accounts of what properties properly make a person a parent, but the authors all rely on there being a sharp distinction between parent and non-parent. Some recent theories have recognised the multiple ways that someone might be thought to be a parent, most notably Bayne and Kolers (2003). We will suggest that only by locating parenting in a set of familial practices can this question be properly understood, let alone answered. One value of this approach is that it removes the necessity of categorising adults in binary fashion as either parents or non-parents, by shifting the focus of attention to doing families, including activities and orientations associated with parenting (see also Sparrman et al. 2016).

Our more general point then, is that it is useful to adopt a definition that recognises how family is necessarily a collection of implicit understandings about expectation, practices and the status of relationships. These are questions that have occupied social scientists and we suggest that there are also practical moral questions that must similarly draw on the best available empirical research to be answered well.

\section{Against Institution and Choice}

Exploring the socio-historical development of the term family (and more latterly families) is helpful in making explicit the aspects of family which are most salient for various authors working on family ethics and problems with these definitions. Specifically, there is often a tendency to want to define family in a way that is static and institutional. By this we mean both that there is an identifiable class of insiders and outsiders and membership of those categories is reasonably stable over time. In this respect, philosophers like Archard mirror the definition of family that dominated 'traditional approaches' in the sociology of family which were strongly in evidence into the 1970s and even 1980s. These were grounded in an attempt to explain the relationship between economic production and social reproduction (the roles of public and private life) and relied on functionalist thinking in which men and women played distinct and complementary roles (Parsons and Bales 1955). This gendered division of labour has to be managed by institutions and therefore interest turned to clearly defining what constitutes a family (amongst other institutions). The definition developed by the social anthropologist, Murdock (1949, p. 11): “A social group characterized by common residence, economic cooperation and reproduction, including adults of both sexes, and one or more children, own or adopted, of the sexually cohabiting adults" brought together the importance of blood/biological relatedness, living arrangements, heterosexuality and generations.

Given these similarities, it is important to note that the reason why over time this definition became discredited is not only its focus on blood ties or heteronormative assumptions. Instead, Murdock's approach faced a combination of criticisms that it is overly abstract, is both ahistorical and historically inaccurate in that it does not (and did not) reflect the reality of diversity in family arrangements, and prioritises a male, white, middle-class perspective on family life. As such, its static and institutional character means that it is not useful in depicting reality or as a basis for political and policy action. In recognising significant problems with Murdock's and similar definitions of family, sociologists attempted to better reflect ideas of relatedness and closeness less bounded by formalised legal and biological structures.

Initially it was changes in family form through increased divorce and remarriage, establishment of blended and step-families that incorporate children who are non-biological children, single parenthood by choice, and increased acceptability and viability of gay couples with children (Treas et al. 2014) that offered a challenge to the boundaries of family and parenthood. And Archard along with Brighouse and Swift and others do, of course, recognise the limitation of overly narrow conceptualisation of family. However, they contend that is sufficient to work with a simpler description that applies to a majority of personal circumstances and then deal with exceptions separately. This suggests the static and institutional model be retained by merely altering some of the parameters of who gets to be a member, for instance a single couple or a gay couple can be classed as parents (see for example 
Brighouse and Swift 2014, p. 48-49). Our contention, following the now dominant sociological position, is that, by its nature, this approach will necessarily be unable to capture the range of close and caring relationships, understood by actors as familial. For example, research on how people who live apart from their partners in Britain describe and understand 'family' has explored how "people in LAT relationships creatively draw and re-draw the boundaries of family belonging in ways that involve emotionally subjective understandings of family life, and that also refer to normative constructions of what 'family' ought to be, as well as to practical recognitions of lived family 'realities'" (Stoilova et al. 2017, p. 78). Relatedly, these shifts led to a clearly demarcated singular 'family' holding less sway in the public imaginary and expectations for family life (see e.g., Giddens 1992).

In sociology, 'families of choice' emerged as a way of thinking that moved beyond institutional framing. This analysis, heavily influenced by insights from feminist theory and anthropology (e.g., Strathern 1992) was based initially on studies of how gay men and lesbians constructed ideas of kinship drawing on ideas of intimacy and reciprocity that did not rely on biological relatedness (e.g., Weeks et al. 2001) and instead drew on the idea of 'elective affinities' (Beck-Gernsheim 1998); as "People with or without legal blood ties who feel that they belong together and wish to define themselves as a family" (Weston 1991). As such it had links to anthropological studies of how personal lives and 'families' could be organised that undermined 'modern' Western household structures and intellectual origins in gender studies that drew attention to the significance of 'doing' gender (e.g., West and Zimmerman 1987) and performativity (e.g., Butler 1990). Definitions of this type both recognise and take seriously the existence of diversity in the practical, everyday organisation of and thinking about families, and decentre heteronormative understandings of how family can and should look.

This more open and agent-centered approach to defining family is recognisable in some recent work in ethical theory. Brake (2010) argues for the concept of 'minimal marriage' which "sets no principles on the sex or number of spouses and the nature and purpose of their caring relationships, nor on which marital rights are exchanged, and whether they are exchanged reciprocally or asymmetrically." (2010, p. 302). In keeping with the families of choice approach, this view permits people to allocate the rights and responsibilities commonly associated with Western ideas of marriage as they choose (Brake 2012, p. 205). She states explicitly that a value of this formulation of marriage is that it "denormalizes heterosexual monogamy as a way of life" and "does not mark some relationships as "legitimate" ... [and] makes new options salient". Cutas and Chan (2012) also argue that there is a need for greater recognition of the diversity and validity of sexual relationships in order to radically reconfigure the family and depart from the nuclear family ideal $(2012$, p. 7). Indeed, they reference the sociological work of Budgeon and Roseneil (2004) in proposing this challenge to heterorelationality which problematises co-residence, romantic love, monogamy and the primacy of the conjugal couple. These authors are correct in challenging the state (and academics) to abandon heterosexuality and coupledom as constituting families, that is, their argument for alternative ways of organising personal relationships are persuasive and give us an attractive ideal. We concur that in a just society that the legal frameworks imagined by authors such as Brake (2010) and Chambers (2017) are convincing: that individuals should have the moral and legal right to enter and exit personal relationships and that the constituent elements of these relationships can be unbundled. Though we consider these ideal questions as important ones for family ethicists to address, we stress that there are important ethical issues arising within the context of actual family life. Towards this end, it is worth seeing why families of choice, while productive in shifting thinking, is somewhat limited in addressing some contemporary issues.

The concern is that the 'families of choice' perspective, especially as interpreted and adopted by analytic theorists, leads, logically, to the term 'family' becoming redundant and replaced by a broader network of significant personal relationships. Among sociologists of family life, some writers would find this move unproblematic and argue that broadening of our thinking about family should indeed lead to a shift in language and a focus on the wider concepts of 'personal life' and 'personal relationships' e.g., (Smart 2007; May 2012). We align ourselves more with Edwards and Gillies (2012) 
who have argued that demoting the term family means that something crucial is missed, both in terms of understanding and analysing contemporary society, and for normative theorising which seeks to address 'social problems'. Similarly for this reason, the philosophical work of Brake and others does not pay sufficient attention to the importance and persistence of dominant practices in everyday family life. In the language of moral theory, many people believe themselves to be under weighty familial duties that do not result directly from their own choices. Indeed, for this reason, people with a legal freedom to act as they wish may feel that they are constrained by social expectations and personal obligations. To give one example, many adults feel a responsibility towards those with whom they have familial relationships that motivate them to care for the elderly or infirm. In liberal societies there is no reason why this responsibility necessarily sits within families but in practice, it does. As Yeandle et al. state "Care is still provided in many-if not all-societies as part of established relationships, particularly within families" (Yeandle et al. 2017, p. 5). Importantly, these are not straightforwardly chosen by individuals but rather are inherited though associations often made through blood, marriage or other longstanding personal connections. Some in the philosophical literature have argued that these may be explained by a principle of delayed reciprocity whereby older children can have a duty of care to their parents owed in light of caring provided to them when they were young (Keller 2006). However, we suggest that this cannot account for the sense of duty to elderly or infirm family, or those requiring some form of specific emotional or practical support that many feel to elderly and infirm family who are not their parents and for whom no direct quid pro quo exists. Nevertheless, this kind of moral relationship is a highly salient one for many people.

Familial structures anchor our experience, are a point of reference even when absent in individuals' own lives, and a source of value. This raises distinctively normative concerns with the families of choice perspective; since by focusing solely on individual 'choice' it ignores the value that people place ongoing expectations and social structures. As Duncan and Edwards (1999) explain, at least in relation to decision making around families, paid work and care, individuals and groups act in ways that are significantly constituted by the social, economic and political context in which they are located. The concept of family gives people powerful reasons for action, that is, people believe they should do what their family requires of them. The choice framework gives no role to moral appraisal and therefore misses an important aspect to the operation of family in contemporary society, where it is commonplace to think of oneself as a 'good' father, sister or niece.

Philosophers could benefit from considering social science research which provide insights into not only the complexity of individuals' views and behaviours but also that these can sometimes be apparently contradictory such as the liberal feminist who nevertheless embraces a white church wedding (see for example Van Hooff 2013). Here we are not interested in the sociological question of why people act in the way they do, rather our aim is to show the important moral values realised by engagement with the way that family is practiced and understood in a particular social context.

\section{Family Practices}

What is then required is an account of family that better captures the complex and intertwined role of individual agency and structural factors: the family practice framework of Morgan and, more latterly, Finch, provides such a theory. Family practices, as developed by (Morgan 1996, 2013) argues that identities are constructed through activities so that "family [is] to be seen as less of a noun"; (Morgan 1996, p. 186) and "represents a quality rather than a thing". Therefore, family scholars should be less interested in defining what a family is and more focused on what families do; "'family' is something that is socially constructed by particular groups of people in their interactions about the meanings of social relationships" (Cheal 2007, p. 7). A useful definition of the family practice approach is provided by Heaphy who writes "Finch's ideas ... are rooted first and foremost in interconnected sociological ideas about 'doing family' and 'family practices'. These emphasise the social and relational through which families are (re)produced: family is defined less by 'blood' or legal ties and more by activities culturally deemed family. 'Doing family' perspectives explore families as social projects 
or achievements. They are concerned with how families are actually lived, and the active part their participants play in shaping them." (Heaphy 2011, p. 21). The virtue of this definition is that it is able to capture the element of agency, flexibility and transformation over time that is consistent with how families are thought about by individuals within them, but, at the same time, it remains grounded in the reality of social institutions and conventions that continue to influence how we think about families and what they should offer members. In contrast to earlier definitions which defined family and then sought to categorise individuals as fitting in or not, this approach starts from looking at everyday lives. Thus, it resolves the problem that many authors get into when trying to define who 'counts' as family in, for example, blended families.

We believe that in translating this sociological approach to a more analytic definition, 'family practices' offers the following way of thinking about family. Family is best thought of as a property of interpersonal relationships, rather than demarcating an institution that is constituted by a set of members. Therefore, our intervention is not to offer a different set of criteria as to who counts as a family member, rather it is to move past the in/out membership idea entirely. We believe that such attempts to define family membership will necessarily fail, as is illustrated by sociological work on the diversity of ways people categorise who is in 'their family' (Spencer and Pahl 2006). To illustrate why, consider who you would include and exclude as being 'your family', for example whether your sister's partner, or mother in law's brother, or your stepfather, or your half-sibling would count. We suggest that while in some cases they definitely would be thought of as family, in other cases they would not; what is used to determine this are practices that can be categorised as familial. It might seem through these examples that we are simply exploiting the fact that families have grey areas or non-solid boundaries but family practices is more radical than this: someone's mother or father can be excluded from their family and inclusion is not reliant on legal, biological or forms of connection that can be expressed in these terms.

What matters is whether two, or more, people together create a set of practices that are properly thought of as familial. Family must thus be (i) enacted, (ii) displayed, and (iii) recognised. Enacted means that family is not a status that a person has, but is created and sustained through action. This need not mean though that family is only created by grand gesture, practices are typically sustained by mundane everyday activities, such as phone calls, sending cards, making a cup of tea. The idea that family must be displayed as well as done was put forward by Finch who emphasises 'the fundamentally social nature of family practices, where the meaning of one's actions has to be both conveyed to and understood by relevant others if those actions are to be effective as constituting 'family' practices.' (2007, p. 66). She argues that familial actions must be linked to what Morgan terms 'wider systems of meaning' i.e., different cultural and social contexts give special significance to certain actions such that these can become familial in the right situation. Display necessarily requires some element of recognition, however, there has been some debate on who is the relevant audience. In Finch's original proposal, family merely required recognition within the appropriate relationship although it may be 'observed' by others. Other authors (see Dermott and Seymour 2011) believe that at least in some cases wider society plays a more fundamental role in confirming practices as familial.

To illustrate the theoretical advantages of family practices, we turn to a case raised by Archard. He argues that when biological parents of a child separate and live apart the "practical necessities of the discharge of the custodial role" mean that the ongoing provision of care implies continuity with a functional understanding of the family and therefore "It does not stretch the concept of 'family' unacceptably to speak of a single family across two houses in these kinds of case" (Archard 2010a, p. 11). Yet, "if each of the adult guardians were to form a new relationship with another partner, and especially if that new relationship came with or resulted in further children, it would make more sense to see the original children as now having two families" (2010a, p. 11).

Archard discusses two situations, either both of the separated parents do have a new partner (therefore the child is judged now to have two families) or the parents both remain single (and the child has a one family that includes themselves and their parents). To illustrate the difficulties of this 
view, and the strengths of the family practice framework, consider the following case. Adam and Betty get together and have a child, Callum. While Callum is a child, the two split up. Following their break up, the two are entirely amicable and Callum lives for an equal time with each adult. While at Betty's house, Callum is also looked after by Betty's best friend Ellen. Later, Adam enters a long-term relationship with Frankie.

One strange feature of Archard's account is that the 'family' of which Betty is a part depends upon the actions of Adam. Straight after their split, Archard's analysis suggests that there remains one family, just one in which the two adults do not cohabit. As Archard realises, an adequate theory of family must make space for the rising prevalence of LATs (living apart togethers), and for the fact that the custodial function of a family could be provided by adults living in nearby houses rather than in the same house. However, once Adam enters the new relationship with Frankie, suddenly Betty is no longer in a family with Adam at all. Now there are two separate families, one constituted by Adam, Frankie and Callum and the other a single parent family where Betty raises Callum alone. Given there is no reason to necessarily think that Adam's new relationship does anything to undermine or change his ongoing connection to Betty and their parenting, this change in Betty's status seems incongruous.

Further problems are raised when we consider the apparently different situations of Frankie and Ellen. According to Archard, because Frankie is in an intimate relationship with Adam, she becomes part of a family (including Callum). In contrast, Ellen, because she is 'just' a friend of Betty's is not in a family of this kind. Suppose however, that Frankie very rarely sees Callum and while she is committed to Adam, she views herself without any significant responsibility for or rights over Callum's upbringing. By contrast, Ellen is central to the provision of Callum's care and does take some responsibility for his wellbeing. To us, there seems good reason to think that how Frankie and Ellen think about their roles as carers and sense of belonging to the family does matter. We believe that this case illustrates not simply that Archard has got his definition of family wrong, but that any understanding of family as a noun will necessarily encounter serious problems. The virtue of the family practice framework is that it understands family as applying to a series of actions and expectations. In the above case, asking whether or not Frankie is part of 'the family' is to ask what role she plays in their daily lives and how she is viewed by Callum. We think that reaching a decision about the distribution of caring rights and responsibilities requires greater sensitivity to the practices and emotions of the parties involved. Current sociological thinking allows for a more bespoke response, but one that is still based on normative principles. We do not say that family practices should simply be reproduced and have intrinsic worth instead we claim that practices need to be taken into account by decision makers given their importance to people's own conception of what constitutes family.

A key element to our argument is that it does not attempt to redefine who is categorised as in or not in a family (and by association who is or is not characterised as a parent) because it rejects the value of viewing these as binary categories. A number of individuals can be engaged in parenting a child over time where this is understood as both providing a range of practical and emotional forms of support that are also related to subjective feelings of intimacy and responsibility. This seems contrary both to widespread popular understanding and social science findings which take seriously the subjective view of individuals and therefore undermine the idea that a single unit of family is conceptually helpful or realistic.

It seems plausible that Ellen feels a deep responsibility towards the child, and appraises her own actions in terms of whether she meets these responsibilities whereas Frankie who is considered a family member under Archard's approach does not believe she has weighty responsibilities, and that Callum himself would not expect Frankie to act as if she had them. On the other hand, it is equally plausible that Frankie is engaged in parenting and has associated ongoing duties towards the child but that she is simply engaged in a different set of parenting practices. To give a real-world example, a non-resident father could have limited regular contact with his child but still engage in practices that he, and the child, see as about parenting (such as buying birthday gifts or texting messages or attending an annual school event) which have their basis in a strong emotional connection and thus 
maintain the relationship as being one between parent and child. Our aim therefore is not to define what can count as a family or parenting practice, but to stress that the family practice approach is deeply contextual and open to a number of possibilities depending on how the participants themselves mutually understand their situation.

\section{The Role of Conventions in Family Practice}

One element to be emphasised with the family practice approach-as highlighted in the example above-is that it draws not only on the perceptions and opinions of individuals and their close intimates but also the expectations of wider society (see (Dermott and Seymour 2011) for a longer discussion of this). This implies that what counts as familial relies on social context; and therefore may appear similar to recent research in the field by Joseph Millum (2018). However, we consider that the family practice framework is distinctive and analytically superior.

Millum understands the parent-child relationship as arising out of a set of social conventions, with the parental obligation being an artificial rather than natural duty. Whereas we agree that it is imperative to connect the ethics of parenting to contemporary social contexts that ultimately create and constitute this category, Millum's theory rests on an overly narrow understanding of what social conventions actually exist. For instance, Millum argues that men come to have strong obligations to children merely by engaging in sexual activity. In this respect, his view is similar to causal theorists, like Archard (2010b); Nelson (1991); Porter (2014), who argue that people acquire parental responsibilities simply by creating a child. Where Millum differs from these theorists, is in arguing that creating children through sex creates obligations only if certain social conventions are in place. He writes:

"parental duties are taken on by individuals through acts whose meaning is determined by social convention .... Given the conventions of the dominant Anglo-American culture, accidental fathers, for example, have taken on responsibility for their children through the act of sexual intercourse" (Millum 2018, p. 79).

We find Millum's intervention in this debate helpful because he draws attention to the intrinsic social construction of categories and activities such as 'parent' and 'parenting'. Therefore, he highlights that they depend upon 'conventions', that is, the moral impact of people's choices relies upon the web of social interactions of which they are a part. We contend that the best available theory of parental obligations must include reference to shared social understandings of what constitutes parenting, and therefore the study of those parental obligations must also closely examine actual social conventions. Seen in this light, many of Millum's arguments appear overly reliant on social norms held only by particular groups. For example, he references the 'Anglo-American culture of parenting' as a determining factor for how a person's duties will be defined whereas 'culture' —as sociology continually shows - is variable over time and place and dependent on social position, and therefore must be problematised.

There is a concern that Millum has adopted a problematic approach where personal experiences and views of cultural practices are accepted as being more widely generalisable. From a Bourdieusian perspective he unreflexively reproduces his own 'habitus', that is his deeply ingrained dispositions, views, and practices. There is then a general concern about taking one set of experiences as accurately reflecting those of the population as a whole when, as sociologists such as (Gillies 2008; Jensen 2018) have outlined, dominant expectations about good parenting privilege middle-class white conventions with respect to activities, behaviour and orientation. Philosophers of family can describe the reasons why people are under moral duties created by social conventions or practices. But a more nuanced specification of these moral duties can be achieved by using better understandings of the practices that are actually in place, which necessarily respond to and engage with social conventions but are not bound by them in an overly simplistic way. Social norms may vary across significant socio-demographic characteristics such as class, location, and ethnicity/race, and they also may be actively created in new ways by individuals rethinking with close others how they construct and enact familial/parenting 
relationships. Our theory thus allows us a more nuanced understanding of 'social context'. We have shown that sociological thinking offers a better route to relevant practices-and therefore moral obligations - than does abstract theory alone because of the dangers of 'commonsense' understandings of families or parents that rely on necessarily limited, experience.

\section{Conclusions}

This paper has shown the wider applicability of a leading sociological theory of family through highlighting its normative importance, showing how families are best understood as constituted as practices within cultural frameworks. Contra many leading family ethicists, we have made the case for seeing 'family' as a distinct and important category that not only has ongoing relevance for understanding contemporary society but also for normative theorizing. We also argue that stipulating narrow definitions of family restricted to the parent-child dyad is unhelpful and that this approach excludes from view important and distinctively familial relationships, which can matter both to childrearing and to adults' interpersonal relationships.

In line with contemporary sociological writing, we have articulated the value in a more nuanced definition of family than those currently dominating some political and policy discourses and described what this could look like. We argue that the best understanding of 'family' is the practice approach; according to this framework, families (following Morgan 1996) are constituted by the doing of family. As such, we can capture familial duties and obligations without having to define individuals as belonging to a particular family. This approach does not rely on families being fixed entities with individuals moving into and out of them. It follows from this that it is not necessary to think of parental status as a simple binary category which people either have or do not have. It also avoids overplaying the extent to which family can be understood as entirely subjectively defined by the individual. 'Family practices' recognises that dividing lines between families which may seem fluid to a degree are also contingent on cultural assumptions and develop over time through everyday practices that are often unreflective and experienced as active choices, i.e., it is often not morally possible for individuals to easily opt in and out of familial relationships. This is productive for current debates in family ethics as it provides a better-in the sense of both more plausible and more useful—definition that can be used to address specific dilemmas. The paper therefore has shown the value of 'family practices' beyond its disciplinary origins in supporting the development of better normative theory: in future we hope to further illustrate the fruitful ways that normative theory can have a dialogic relationship with empirical social science.

Author Contributions: Both authors jointly conceptualized, wrote, and edited the paper, and agree with the published version of the manuscript. All authors have read and agreed to the published version of the manuscript.

Funding: This research received no external funding.

Conflicts of Interest: The authors declare no conflicts of interest.

\section{References}

Archard, David. 2010a. The Family: A Liberal Defence. London: Palgrave Macmillan.

Archard, David. 2010b. The Obligations and Responsibilities of Parenthood. In Procreation and Parenthood. Edited by David Archard and David Benatar. Oxford: OUP.

Austin, Michael. 2007. Conceptions of Parenthood. Burlington: Ashgate.

Bayne, Timothy, and Avery Kolers. 2003. Towards a Pluralistic Account of Parenthood. Bioethics 17: $221-42$. [CrossRef] [PubMed]

Beck-Gernsheim, Elisabeth. 1998. On the Way to a Post-familial family: From a community of need to elective affinities. Theory Culture and Society 15: 53-70. [CrossRef]

Brake, Elizabeth. 2010. Minimal marriage: What political liberalism implies for marriage law. Ethics 120: 302-37. [CrossRef]

Brake, Elizabeth. 2012. Minimizing Marriage: Marriage, Morality, and the Law. Oxford: OUP. 
Brighouse, Harry, and Adam Swift. 2014. Family Values: The Ethics of Parent-Child Relationships. Princeton: Princeton University Press.

Budgeon, Shelly, and Sasha Roseneil. 2004. Beyond the Conventional Family. Current Sociology 52: 123-25. [CrossRef]

Butler, Judith. 1990. Gender Trouble. New York: Routledge.

Chambers, Clare. 2017. Against Marriage: An Egalitarian Defense of the Marriage-Free State. Oxford: Oxford University Press.

Cheal, David. 2007. Families in Today's World. London and New York: Routledge.

Cutas, Daniela, and Sarah Chan. 2012. Introduction: Perspectives on Private and Family Life. In Families- Beyond the Nuclear Ideal. Edited by Cutas Daniela and Chan Sarah. London: Bloomsbury.

Dermott, Esther, and Julie Seymour, eds. 2011. Displaying Families: A New Concept for the Sociology of Family Life. London: Palgrave Macmillan.

Duncan, Simon, and Rosalind Edwards. 1999. Lone Mothers, Paid Work and Gendered Moral Rationalities. London: Palgrave.

Edwards, Rosalind, and Val Gillies. 2012. Farewell to family? Notes on an argument for retaining the concept. Families, Relationships and Societies 1: 63-69. [CrossRef]

Finch, Jane. 2007. Displaying Families. Sociology 41: 65-81. [CrossRef]

Gheaus, Anca. 2018. Biological Parenthood: Gestational, Not Genetic. Australasian Journal of Philosophy 96: 225-40. [CrossRef]

Giddens, Anthony. 1992. The Transformation of Intimacy: Sexuality, Love and Eroticism in Modern Societies. Cambridge: Polity Press.

Gillies, Val. 2008. Childrearing, Class and the New Politics of Parenting. Sociology Compass 2: 1079-95. [CrossRef]

Heaphy, Brian. 2011. Critical Relational Displays. In Displaying Families: A New Concept for the Sociology of Family Life. Edited by Dermott Esther and Seymour Julie. London: Palgrave Macmillan.

Jensen, Tracey. 2018. Parenting in Crisis. Bristol: Policy Press.

Keller, Simon. 2006. Four theories of filial duty. The Philosophical Quarterly 56: 254-74. [CrossRef]

MacDonald, Mandi, Hayes David, and Houston Stan. 2018. Understanding informal kinship care: A critical narrative view of theory and research. Families Relationships and Societies 7: 71-87. [CrossRef]

May, Vanessa. 2012. Are we really saying farewell to family? A response to Edwards and Gillies 'Farewell to family'? Families Relationships and Societies 1: 425-21. [CrossRef]

Millum, Joseph. 2018. The Moral Foundations of Parenthood. Oxford: Oxford University Press.

Morgan, David. 1996. Family Connections: An Introduction to Family Studies. Cambridge: Polity Press.

Morgan, David. 2013. Rethinking Family Practices. London: Palgrave Macmillan.

Murdock, George. 1949. Social Structure. New York: Macmillan.

Nelson, James Lindemann. 1991. Parental Obligations and the Ethics of Surrogacy: A causal perspective. Public Affairs Quarterly 5: 49-61. [PubMed]

Parsons, Talcott, and Robert Bales. 1955. Family, Socialization and Interaction Process. New York: Free Press.

Porter, Lindsay. 2014. Why and How to Prefer a Causal Account of Parenting. Journal of Social Philosophy 45: 182-202. [CrossRef] [PubMed]

Powell, Catherine. 2018. Care for older people in multigenerational families: A life course analysis across four generations. Families Relationships and Societies 7: 103-21. [CrossRef]

Smart, Carol. 2007. Personal Life. London: Sage.

Sparrman, Anna, Westerling Allan, Lind Judith, and Dannesboe Karen Ida, eds. 2016. Doing Good Parenthood: Ideals and Practices of Parental Involvement. London: Palgrave Macmillan.

Spencer, Liz, and Ray Pahl. 2006. Rethinking Friendship: Hidden Solidarities Today. New Jersey: Princeton University Press.

Stoilova, Mariya, Roseneil Sasha, Carter Julia, Duncan Simon, and Phillips Miranda. 2017. Constructions, reconstructions and deconstructions of 'family' amongst people who live apart together (LATs). British Journal of Sociology 68: 78-96. [CrossRef] [PubMed]

Strathern, Marilyn. 1992. After Nature. Cambridge: Cambridge University Press.

Treas, Judith, Scott Jacqueline, and Richards Martin. 2014. The Wiley Blackwell Companion to the Sociology of Families. Chichester: Wiley and Sons.

Van Hooff, Jenny. 2013. Modern Couples? Continuity and Change in Heterosexual Relationships. Farnham: Ashgate. 
Velleman, J. David. 2005. Family History. Philosophical Papers 34: 357-78. [CrossRef]

Weeks, Jeffrey, Heaphy Brian, and Donovan Catherine. 2001. Same-Sex Intimacies: Families of Choice and other Life Experiments. London and New York: Routledge.

West, Candace, and Don H. Zimmerman. 1987. Doing Gender. Gender and Society 1: 125-51. [CrossRef]

Weston, Kath. 1991. Families We Choose: Lesbian, Gays, Kinship. New York: Columbia University Press.

Yeandle, Sue, Yueh-Ching Chou, Michael Fine, Mary Larkin, and Alisoun Milne. 2017. Care and caring: Interdisciplinary perspectives on a societal issue of global significance. International Journal of Care and Caring 1: 3-25. [CrossRef]

(C) 2020 by the authors. Licensee MDPI, Basel, Switzerland. This article is an open access article distributed under the terms and conditions of the Creative Commons Attribution (CC BY) license (http://creativecommons.org/licenses/by/4.0/). 